\title{
Starting a Rookie FIRST Robotics Competion Team: Lessons Learned
}

\section{Dr. Lynn A. Albers, Campbell University}

Dr. Lynn Albers is Founding Assistant Professor of the newly formed School of Engineering at Campbell University. A proponent of Hands-On Activities in the classroom and during out-of-school time programs, she believes that they complement any teaching style thereby reaching all learning styles. She earned her doctorate in Mechanical Engineering from North Carolina State University where her research spanned three colleges and focused on Engineering Education. Her passions include but are not limited to Engineering Education and Energy Engineering. In addition, she has been lead mentor of FRC Team SUM \#6003 for the past two years.

\section{Dr. Jenna P. Carpenter, Campbell University}

Dr. Carpenter is Founding Dean of Engineering at Campbell University. She is Chair of the ASEE Long-Rangge Planning Committee and the ASEE Strategic Doing Governance Team. She is a past Vice President of Professional Interest Councils for ASEE and past President of WEPAN. Currently Chair of the National Academy of Engineering Grand Challenge Scholars Program Steering Committee and an ASEE PEV for General Engineering, Dr. Carpenter regularly speaks at the national level on issues related to the success of women in engineering and innovative STEM curricula.

Ms. Marie E. Hopper, FIRST North Carolina 


\title{
Starting a Rookie FIRST Robotics Competition (FRC) Team: Lessons Learned
}

\begin{abstract}
FIRST - For Inspiration and Recognition of Science and Technology - is a global program that inspires students to learn and love STEM. FIRST Robotics Competition (FRC) engages students in grades 9-12 to design and build a robot according to the competition specifications revealed at kick-off; marking the start of build season which lasts a little over six weeks. The students then travel to district events where a drive team of four students operates the robot; competing in numerous matches over a two-day period to earn ranking points and ultimately qualifying for the State Competition.
\end{abstract}

FRC is an excellent hands-on activity that promotes intellectual and emotional growth for all students involved. ${ }^{1}$ The opportunity for learning is immeasurable thereby making participation in FRC highly desirable. There is a need for more teams in order to give more students this learning opportunity. Unfortunately, the demand for more teams is coupled with a deficit of mentors. Many adults feel unqualified to mentor for numerous reasons. It is hoped that by sharing lessons learned of five, successful rookie teams, more adults will realize their potential for mentoring and/or starting a FRC team.

The 2016 FRC season was filled with excitement, a challenging competition design (FIRST Stronghold), and many talented youth, mentors, and leaders. This paper focuses on the lessons learned from five, successful rookie teams; analzying the data for common themes. The teams have provided lessons learned from the perspective of the lead mentors, specialized mentors, and the students; thereby creating a comprehensive list of helpful hints, techniques and strategies.

A reminder, the FIRST competition is more than robots. It's about people, it's about learning to work together, it's working together toward a shared goal, doing teamwork, it's about finding and using each individual's unique talent to make the project team greater than the sum of its parts. It's about applying skills that will lead to success in whatever you do in life.

John Abele, Chairman of the Board, FIRST

Universities are increasingly partnering with FIRST by either sponsoring a team and/or hosting a regional event ${ }^{3}$ as a way to recruit top students. However, the program is very mentor dependent; i.e. it takes more than one adult to lead a team. Because we live in a society with a growing need to become more technologically literate ${ }^{2}$, because FRC is 
very time dependent, because FRC is expensive, and because the first year can be very overwhelming, there is a shortage of mentors. For those willing to start an FRC team, there is a great deal of support as everyone is encouraged by FIRST to act with "gracious professionalism" " and to engage in "coopertition" not only during build season and competition season but all the time. Veteran teams reach out to and support rookie teams not only with materials but with knowledge and guidance. This paper presents some of the knowledge that rookie teams return to the FIRST community.

\section{Methodology}

Five rookie teams from the 2016 season willingly provided their lessons learned for this paper. (See Appendix.) The teams were all from North Carolina and had submitted the lessons learned at the end of the season as fulfillment of the requirements for the Argosy Foundation Rookie Grant. The author had hypothesized that the lessons learned would be focused more on learning mechanical aspects; such as for each wheel, one must order a wheel hub which can be a $1 / 2$ " hex, a $3 / 8$ " hex, or a $1 / 2$ " round with $1 / 8$ " keyway. This in turn has to match the gearbox output shaft; another item ordered separately. Gearboxes can be ordered with several 4:1 reduction stages that can be combined to give 4:1, 16:1, 64:1 or 256:1 reductions. However, if more specialized reductions, such as 9:1, 10:1, or 12:1 are required, then planetary gearboxes can be ordered and assembled; making sure to order the ring gear which is separate from the gear kit and typically sells out half way through build season as do 3:1 gear kits and 5:1 gear kits. The latter being a lesson learned. Note that grease and bolts are not included and it does not state in the assembly directions that one must grease up all gears before attaching the gear box to the motor; another lesson learned. Once one decides what parts to order, then comes the question of which distributor is the best to order from. This is analogous to a potter throwing clay and successfully making a bowl only to then have to figure out which glazes to use.

The lessons learned are listed in the Appendix. It can be noted that they did not include mechanical advice other than from Team 6214, "Check your connections and make sure you can't rip them out by hand. If you can then they will fall out after your first obstacles for every match until you replace every weak connection."

The lessons learned primarily included advice on mentors, funds, and time management.

Mentors: Team 5854 stated, "One or two mentors are NOT enough.

To really keep a team busy, happy, etc. you need a veritable army of helpers and mentors. Not just propeller heads (the techy types), also need food people, fundraisers, organizers, artists, business managers and so on. All skills are useful." Team 6214 stated, "Start looking for mentors early. We were only able to get mentors at the end of the build season, and although we did not get any direct money sponsorships. The sponsorship we did get was facilitated by the mentors in the community." 
Fundraising: Team 5854 "FRC is expensive. REALLY expensive. It can be done on a shoestring, but not well. Whatever you budget, double or triple it. Then you MAY have enough."

Team 6004 "We struggled to purchase needed equipment and learned the value of getting sponsorships to help with the cost."

Team 6214, "Fundraise as much money possible before competition that way we won't have stress about the cost and instead can focus more on making sure the robot is ready to go."

Team 6215, "Having community support and corporate sponsorships make resources more readily available and promotes sustainability and successful outcomes. Fundraise 24/7."

Time Management: Team 5854, "Design the best bot you can. Build as much of it as you can during build season. Then continue to make it better throughout the competition season. If your state is district use the 6 work hours in between competitions. You ARE allowed to modify your robot. Prepare everything you need to change, repair, or work on before you unbag, schedule out your unbag time. Then unbag- you can be way more efficient in your unbag time this way."

Team 6003, "The most productive days of the week were Friday evenings (usually 5-10 p.m.) and Saturdays starting at 10 a.m. and going until 6 or 7 p.m. Taking time off is necessary so it is better not to meet every day. Moving forward, we will not meet on Sundays and will take one evening off during the week. Wednesday night is a good choice because it is a busy church night and a good time during the week for students to study/prepare for exams which are typically given on Fridays."

Team 6004, "Keep up with your build time and cut off dates; time management is a necessity."

\section{NVivo Analysis of Lessons Learned}

The lessons learned were analyzed using NVivo to see if any other common themes emerged. A Word Cloud - where the more frequently used words are emphasized - was created for each team. A total Word Cloud was created for all lessons learned combined. 


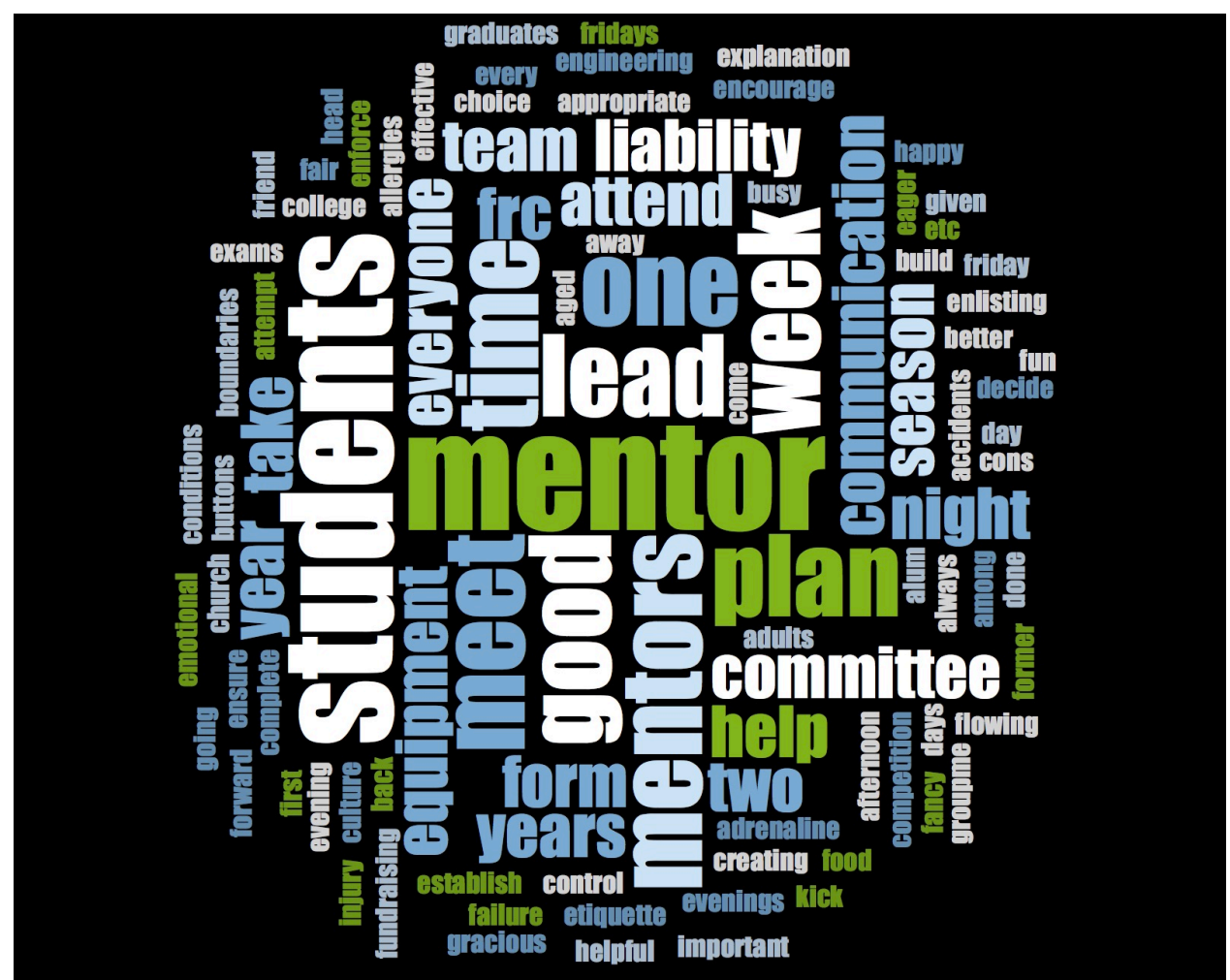

Figure 1: Team 5854 Word Cloud

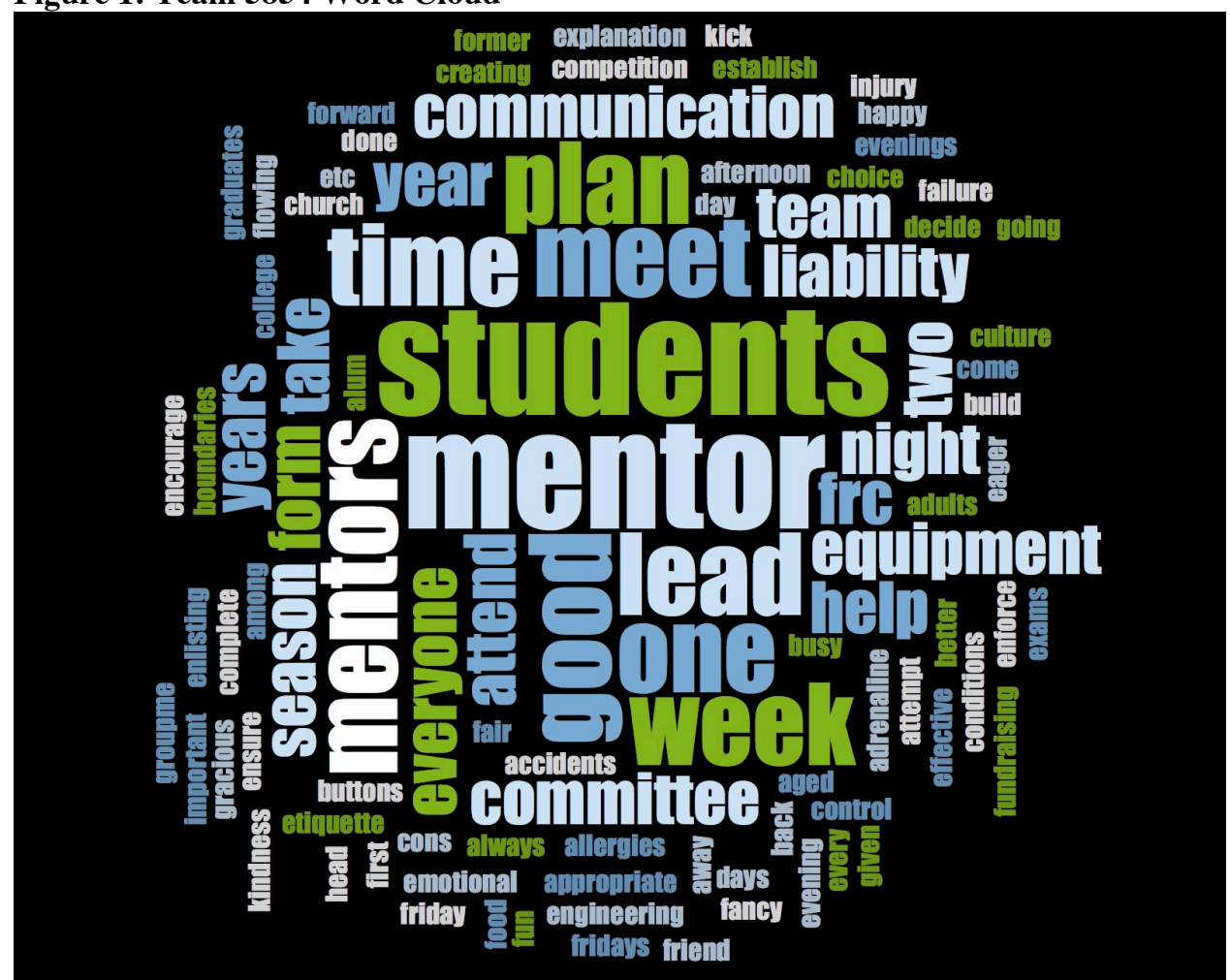

Figure 2: Team 6003 Word Cloud 


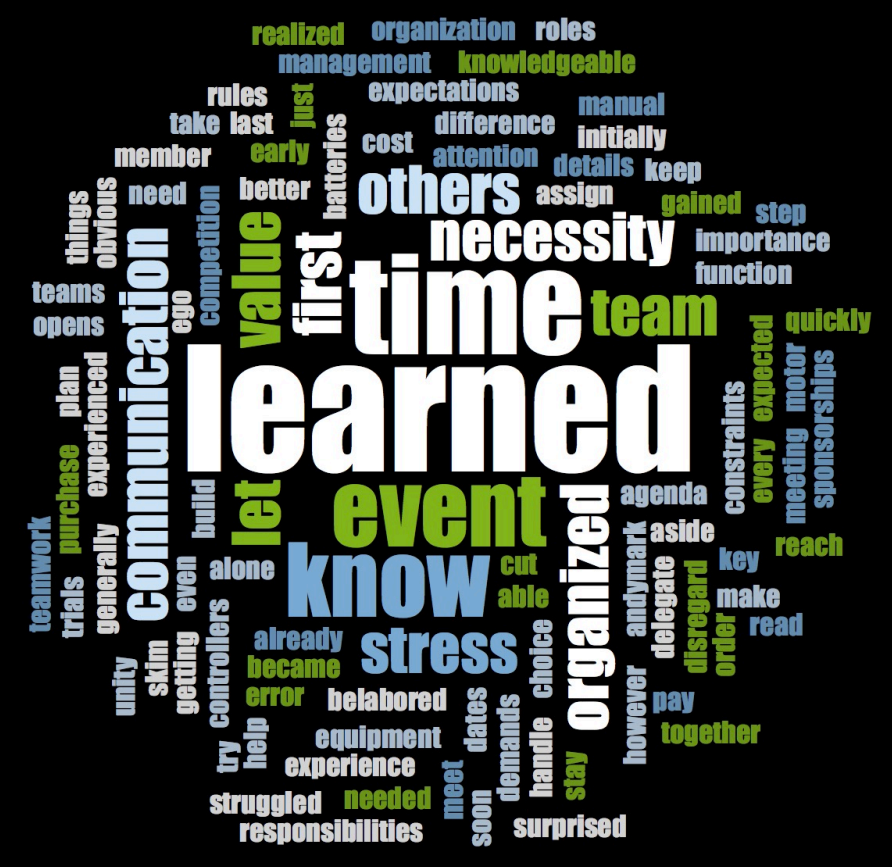

Figure 3: Team 6004 Word Cloud

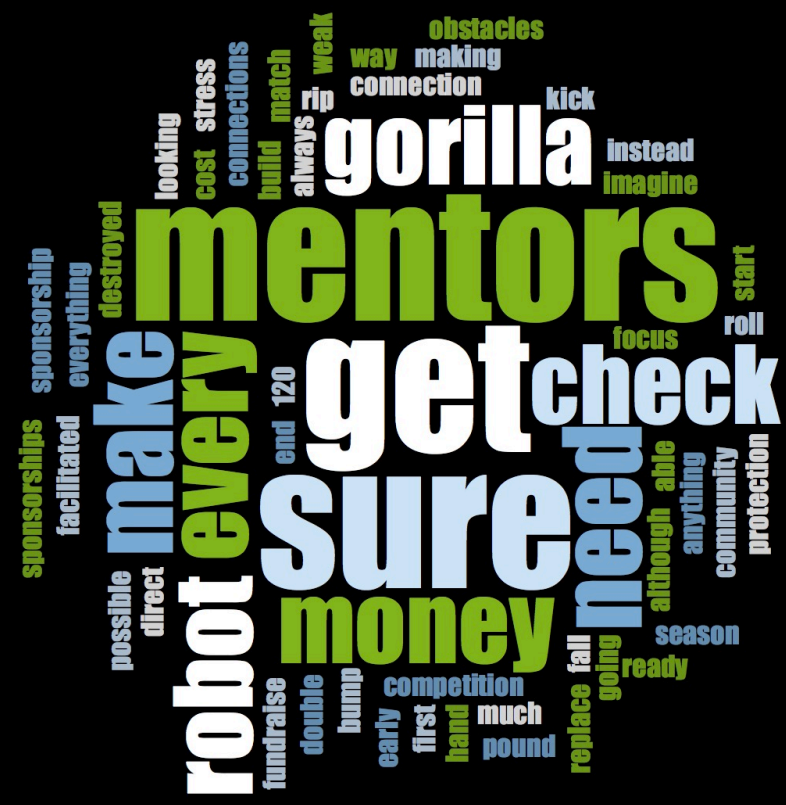

Figure 4: Team 6214 Word Cloud 


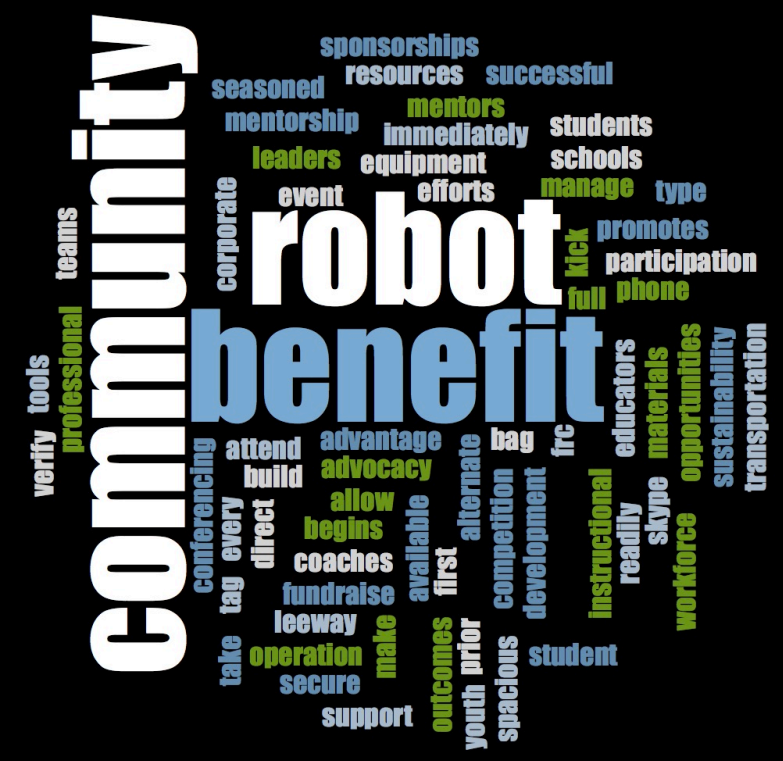

Figure 5: Team 6215 Word Cloud

Figure 6: Total Word Cloud

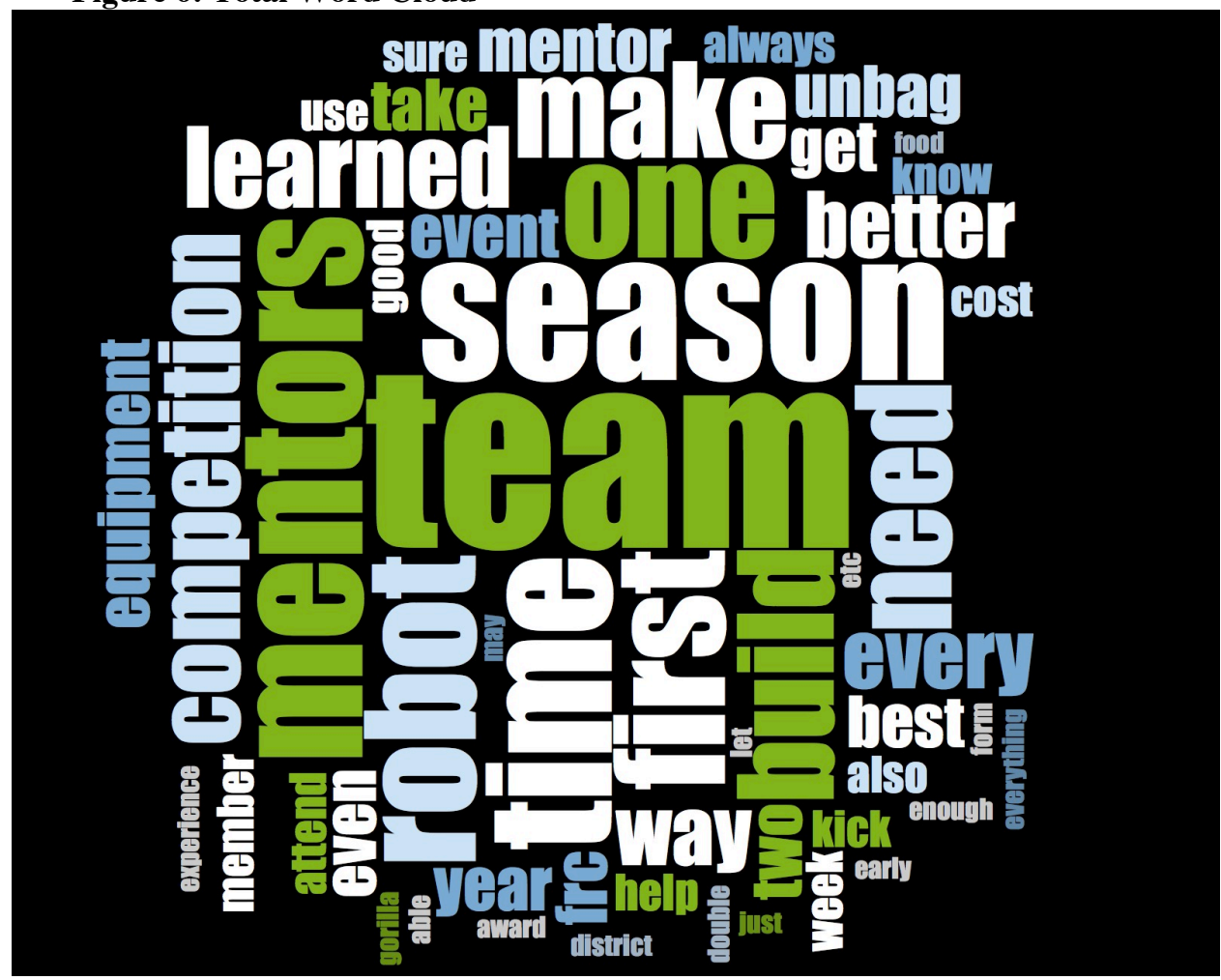

All the lessons learned were coded and the below themes emerged. It is interesting to note that the lessons learned do not include technical advice such as how to wire, build or 
program the robot. They touch upon the other aspects of running a successful team such as fundraising, materials, time management (build season, preparation for competition), communication, mentoring and designing.

Theme

Build Season

Fundraise

Materials

Preparation for Competition

Team Mentors

Communication

Networking

Kick-Off

Strategy

$\begin{array}{cc}\text { Sources } & \text { References } \\ 5 & 8 \\ 4 & 7 \\ 4 & 4 \\ 4 & 11 \\ 4 & 5 \\ 3 & 9 \\ 3 & 7 \\ 2 & 3 \\ 2 & 3\end{array}$

A hierarchy chart was created based on the number of references as shown in Figure 7.

Figure 7: Hierarchy chart - references

\begin{tabular}{|l|l|l|l|l|}
\hline Preparation for competition & Buld Season & Fundraice & Mater... & Sust... \\
& & & & \\
\hline Communication & Networking & Team Mentors & Strategy \\
\cline { 4 - 5 } & & & Fekooff \\
\hline
\end{tabular}

Due to the nature of build season - where teams have 6.5 weeks to design and build a working robot - it is not a surprise that there were many lessons learned by all five teams about the build season. The time constraint imposes a certain sense of urgency that makes it imperative to prepare as much as possible before build season starts.

A great deal of preparation also goes into the competition; more than one can anticipate. In addition to creating a working robot, one must plan logistics such as room and board, transportation, outfitting the pit, and preparing buttons.

\section{Discussion}

As a lead mentor, the number one excuse heard from other adults when asked to mentor is, "I know nothing about robots." Yet, none of the lessons learned were centered around technical knowledge of robots. There was no mention of materials, fabrication, assembly, wiring, 
programming or testing. There can be several reasons for this; the mentors were already technically savy; they didn't think there was a need to share lessons learned around technical knowledge; or they didn't think it was a lesson learned. There were several lessons learned in the telling of the wheel story alone. First lesson learned is that wheels don't come with hubs to attach them to shafts. Perhaps even another lesson is that wheels must be attached to shafts. Then, the shaft shape has to match the hole shape on the hub. Etc. For someone who has never assembled a robot, these are all lessons learned yet none (or something similar) were reported. If we are to empower adults who have never built a robot to mentor students, lessons learned such as these would prove to be very valuable guidance and help reduce the fear factor of the task at hand.

Another option is that those from each team who contributed to the lessons learned only contributed what impacted them directly. Perhaps more students than mentors were surveyed? If students were surveyed, did they make the connection to state what had been learned? Perhaps they don't understand the delta in their knowledge due to the experience.

Future pre- and post-season surveys to gage the delta in knowledge from having performed the activity would be beneficial to deducing the lessons learned and how much are relative to technical knowledge gained vs. other knowledge. Also, the expense and time commitment may play a more important role and are worth investigating.

One could tentatively conclude that the technical aspect of FRC is not as overwhelming as one might think; which might be, in the minds of some, the biggest deterrent. If we can eliminate this fear factor, then perhaps more adults will try mentoring.

\section{Acknowledgements}

The author would like to thank FRC Teams 5854, 6003, 6004, 6214, and 6215 for sharing their lessons learned. A special thank you to NC FIRST for their support compiling this information.

\section{References}

1. Melchior, A., Cohen, F., Cutter, T., \& Levitt, T. (2005, April). More Than Robots: An Evaluation of the FIRST Robotics Competition Participant and Institutional Impacts. Retrieved from http://dev1.raiderrobotix.org/wp-content/uploads/2012/08/FRC_eval_finalrpt.pdf

2. Pearson, G., \& Young, A. T. (2001). Technically Speaking: Why All Americans Need to Know More About Technology. Washington, DC: National Academy Press.

3. Wilczynski, V., \& Flowers, W. (2006). FIRST Robotics Competition: University Curriculum Applications of Mobile Robots*. International Journal of Engineering Education, 22(4), 792803.

4. FIRST. (2017). Gracious Professionalism. Retrieved from http://www.firstinspires.org/roboticsprograms/frc/blog-Gracious-Professionalism 


\section{Appendix - Lessons Learned}

Team 5854

- Design the best bot you can. Build as much of it as you can during build season. Then continue to make it better throughout the competition season. If your state is district use the 6 work hours in between competitions. You ARE allowed to modify your robot.

- While you're in design mode you should think about upgrades to be implemented throughout the competition season.

- Prepare everything you need to change, repair, or work on before you unbag, schedule out your unbag time. Then unbag- you can be way more efficient in your unbag time this way.

- As a team, we realized that working together was the best way to accomplish tasks.

- Mechanical build lead - I realized that even though I may not have the most experience building robots or working with machines, I could quickly learn, and that everyone was also learning as they progress through the season.

- We discovered that the best solution to a problem wasn't necessarily the first idea, or even the first thing we built. The team continued changing and making the robot better all the way through the season, even at the national competitions! Our robot was always changing and evolving, and that's one of the main things that helped us get to the FIRST Championship.

- Outreach is very important for the Rookie All-Star award, as well as the Chairman's award in the future. From starting and mentoring an FLL team to doing a small bristlebot workshop, all outreach is important and the more of it you do the better.

- $\quad$ FRC is expensive. REALLY expensive. It can be done on a shoestring, but not well. Whatever you budget, double or triple it. Then you MAY have enough.

- One or two mentors are NOT enough. To really keep a team busy, happy, etc. you need a veritable army of helpers and mentors. Not just propeller heads (the techy types), also need food people, fundraisers, organizers, artists, business managers and so on. All skills are useful.

- Longevity is essential. Any team can make it through one year. Years two, three and beyond are the real test.

- Recruit young kids. A team of all seniors is great...for one year!

- Thank your sponsors and supports profusely, leave no-one out. They are your future.

- In addition to printing a free shirt for each team member and qualifying sponsors, I wish we had taken orders for shirts (at cost) for team member's families and for additional shirts for team members.

- I also wish we had planned in advance for the possibility of traveling to St. Louis and staying at a hotel. We learned that travel arrangements around the Championship are hard (or expensive) to make at the last minute.

- It is important to understand the game thoroughly and to figure out the best strategy to score the most points. This is very important to do before designing the robot.

Team 6003 
- It is important for the team to establish its own culture complete with rules for communication, etiquette, appropriate language, and an understanding of and respect for each other's physical and emotional boundaries.

- All communication should be done by a small committee with the Lead Mentor as the head of the committee in order to ensure quality and control.

- There were pros and cons to using Groupme.

- T-shirts, buttons, and wristbands matter!

- There is a wonderful network of support among the lead mentors and everyone is happy to help.

- Plan to attend THOR and have fun!

- 3D printed parts are effective

- Enforce the "one-year (or two-year) rule." Encourage all recent graduates to take one or two years away from FRC and then decide if they would like to come back and mentor. This is very wise, very fair, and proactively prevents problems.

- The most productive days of the week were Friday evenings (usually 5-10 p.m.) and Saturdays starting at 10 a.m. and going until 6 or 7 p.m. Taking time off is necessary so it is better not to meet every day. Moving forward, we will not meet on Sundays and will take one evening off during the week. Wednesday night is a good choice because it is a busy church night and a good time during the week for students to study/prepare for exams which are typically given on Fridays.

- You don't need fancy equipment (such as a lathe, mill, ShopBot) to survive your first season. These pieces of equipment are helpful but can be purchased after several years of successful fundraising

- Any new mentors and students should plan to attend the kick- off in person and stay for the afternoon help sessions.

- Students signed up more quickly (and were more eager) than the adults.

- Meet and friend as many other team leaders as possible. There is a wealth of knowledge, kindness and gracious professionalism.

- Mitigating failure by creating an engineering rollout plan should be taught (or at least an attempt at an explanation) during the pre-season. Teaching it during competition when everyone is tired, stressed, and adrenaline is flowing is not a good time.

- Have all students and mentors sign a liability form protecting them from any form of liability such as an injury in the build space, accidents while traveling, food allergies, medical conditions, etc.

- Always reach out to their former lead mentor for a reference before enlisting a college aged FRC alum as a mentor.

Team 6004

- Use First Choice from Andymark quickly, as soon as it opens order batteries and motor controllers.

- Do not disregard the necessity of team communication.

- Make a plan or agenda for every meeting; organization is key.

- Keep up with your build time and cut off dates; time management is a necessity. 
- Don't just skim the rules, but pay attention to the details. Read the manual early so you know what is expected of you.

- Don't try to "go-it-alone." Reach out to other teams. You will be surprised at what others already know.

- Let go of the ego. Know when you need to step aside and let others, more experienced or knowledgeable, take over.

- We struggled to purchase needed equipment and learned the value of getting sponsorships to help with the cost.

- We learned to delegate responsibilities, assign roles, and generally be more organized. There was an obvious difference between the first event and the last event.

- With the time constraints of the competition, we learned how to function under stress. Initially, we didn't handle this well. However, as we gained experience and realized the expectations for the event, we became more organized and better able to meet the time demands.

- Through trials of error, stress, and belabored communication, we learned the importance of teamwork and unity. We learned to value each member of the team and stay together even when things go wrong.

Team 6214

- Start looking for mentors early. We were only able to get mentors at the end of the build season, and although we did not get any direct money sponsorships. The sponsorship we did get was facilitated by the mentors in the community.

- Check your connections and make sure you can't rip them out by hand. If you can then they will fall out after your first obstacles for every match until you replace every weak connection.

- Imagine a 120 pound gorilla is going to bump, kick, and roll over your robot. If anything can be destroyed by the gorilla it will need protection.

- Fundraise as much money possible before competition that way we won't have stress about the cost and instead can focus more on making sure the robot is ready to go.

- Always double check to make sure if we have everything we need.

Team 6215

- Having community support and corporate sponsorships make resources more readily available and promotes sustainability and successful outcomes. Fundraise 24/7.

- Every type of student can benefit from participation in FIRST.

- The professional development of students/instructional/community leaders is a direct benefit to schools and the youth advocacy efforts of educators and the workforce

- Allow Alternate Coaches and Mentors the leeway to manage the build season; but verify full operation of the robot immediately prior to tag and bag and before each competition.

- Attend the kick-off event and take advantage of skype, phone conferencing and mentorship opportunities by more seasoned FRC Teams.

- Secure robot transportation with spacious equipment for tools and materials before the season begins. 